\title{
EFFECT OF BULLET SHAPE AND $h / a$ RATIO ON BALLISTIC IMPACT BEHAVIOUR OF FRP COMPOSITE PLATE: A NUMERICAL STUDY
}

\author{
Md. Muslim Ansari ${ }^{1}$, Anupam Chakrabarti ${ }^{2}$ \\ ${ }^{1}$ Research scholar, Indian Institute of Technology Roorkee, Roorkee, India \\ ${ }^{2}$ Associate Professor, Indian Institute of Technology Roorkee, Roorkee, India
}

\begin{abstract}
In this paper, the behaviour of FRP composite plate has been studied under ballistic impact with different shapes of impactor and incidence velocity ranging from $100 \mathrm{~m} / \mathrm{s}$ to $1000 \mathrm{~m} / \mathrm{s}$. Damage behavior of plate, the variation of residual velocity and ballistic limit have been studied with different h/a ratios and nose shapes of impactor. A simplified 3D finite element model for composite plate and impactor with gap interaction and Lagrangian mesh has been presented. Progressive damage based on material stress/strain failure criteria incorporation with shock effect is considered to study the stage wise damage evolution in FRP composite plate due to ballistic impact by conical as well as blunt shaped cylindrical bullet in AUTODYN hydro code. FE models are validated with available literature in terms of numerical values of residual velocity and damage pattern in composite plate and show a close agreement.
\end{abstract}

Keywords: FE model, impactor shapes, progressive damage, h/a ratio, ballistic impact.

\section{INTRODUCTION}

The need of high stiffness, high strength and light weight material for structural application has increased the use of fiber reinforced composite material like GFRP, CFRP, Kevlar/epoxy and graphite epoxy composite etc. Due to high stiffness and light weight, FRP composites are widely used in structural application like artificial swimming pools, racing bikes and cars, roof sheeting etc. Kevlar epoxy composite material has high thermal resistance and hence serves as a shield in many environments such as in helicopters, tanks and body armors etc. [1].

Mostly Composite material is orthotropic in nature and hence structures made of FRP composite are vulnerable to damage due to impact and complicated nature of damage draws the attention of researchers. Damage behavior in terms of initiation and propagation is quite considerable to access the suitability for structural application. Significant works have been carried out on the behavior of composite under impact loading. However, the work on ballistic behavior to predict the nature of failure, particularly in the case of Kevlar/epoxy composite is still in queue. Zhu et al. [1] performed experimental investigation to study the ballistic limit of Kevlar/polyester laminate under dynamic penetration by conical bullet. The dynamic test was executed using pneumatic and powder guns. Muhi et al. [2] worked on hybridization of glass fiber reinforced composite with Kevlar 29 and finally hybridized plate was impacted by steel bullet. Energy absorption in the plate had been studied for different combination of glass fiber and Kevlar 29 fiber. Conclusion was drowning that the plate with Kevlar 29 fiber at back face was resistant against penetration than the plate with Kevlar 29 fiber on the front face. Response of Kevlar 29 and 129 composites under impact were studied by Gover et al. [3] but the incidence velocity was limited between $130-250 \mathrm{~m} / \mathrm{s}$, which were below the penetration limit of the panel. Numerical investigation was also carried out in LSDYNA to study the back plane displacement of plate. Minh et al. [4] performed a numerical investigation on 2D Kevlar KM2 plain woven fabric to study the damage behavior. Square plate was impacted by a spherical ball with incidence velocity up to 250 $\mathrm{m} / \mathrm{s}$. Some other numerical investigations had been carried on the Kevlar fiber to study the behavior under impact $[5,6]$. Analytical work on impact performance of hybrid composite made of Kevlar 29 and $\mathrm{Al}_{2} \mathrm{O}_{3}$ powder /epoxy under high velocity impact was carried out by Talib et al. [7]. A relation between ballistic limit and thickness of composite plate had been established. An analytical model proposed by Landa and Olivares [8] to study the impact behavior of soft armors. Assumptions made in this analytical model were; perfectly rigid projectile, uniform deceleration of projectile from one yarn to another and no friction between impactor and target etc. Wen $[9,10]$ studied the behavior of FRP laminated composite plate under high velocity impact with different nosed shaped impactor and presented an analytical model.

In this paper, a 3D FE model has been presented to study the behavior of damage and its progressive nature in composite plate under ballistic impact. Mesh convergence study has been carried out to find the optimized results. Modes of failure in 
composite plate have been discussed at different time during perforation by conical and blunt ended cylindrical bullet. Effect of $h / a$ ratio (where $h=$ thickness of composite plate, $a=$ side of plate) and impactor nose shape on residual velocity and ballistic limit has been discussed. All the numerical simulations have been carried out using ANSYS/AUTODYN v14.5 hydro code.

\section{NUMERICAL AND MATERIAL MODELLING}

Composite plate of size $100 \mathrm{~mm}$ x $100 \mathrm{~mm}$ and impactor made of steel 4340 with apex angle $90^{\circ}$ and $180^{\circ}$ have been used in the analysis. Mesh division of $100 \times 100$ for the composite plate has been chosen for the study under fully clamped boundary condition after mesh convergence study as shown in Figure 1-2. Computational domain for the composite plate is defined in $I-J-K$ space with $I$-MAX $=51, J$-MAX $=51, K$ MAX $=21$ and it is constrained at $I=51$ and $J=51$ planes. Computational domain for steel impactor in $I-J-K$ space is $I$ $\mathrm{MAX}=6, J-\mathrm{MAZ}=6$ and $K$-MAX $=14$ for conical impactor. Gap interaction method is used in this simulation with gap size of 0.009 . A uniform cell size of $0.5 \mathrm{~mm}$ is used in both $I$ and $J$-directions at impact region which constitute $10 \mathrm{~mm} \times 10$ $\mathrm{mm}$. The material properties of Kevlar/epoxy and steel 4340 have been taken from literature [11-12] as shown in Table 1 . Failure initiation criteria and growth of damage in composite is based on the combination of material stress and strain. Hashin failure criteria is used extensively for the modeling and to study the damage in composite due to impact. However, this criterion for matrix and fiber failure is considered only plain stresses $\sigma_{22}, \sigma_{33}$ and $\sigma_{23}$. Modified version of these failure criteria along with the criteria for delamination has implemented in AUTODYN. In the fiber failure and matrix cracking, out of plan shear stresses are also considered with original criteria as in Equations (1-3);

Failure along 11 plane,

$$
e_{11 f}^{2}=\left(\frac{\sigma_{11}}{\sigma_{11 f}}\right)^{2}+\left(\frac{\sigma_{12}}{\sigma_{12 f}}\right)^{2}+\left(\frac{\sigma_{31}}{\sigma_{31 f}}\right)^{2} \geq 1
$$

Failure along 22 plane,

$$
e_{22 f}^{2}=\left(\frac{\sigma_{22}}{\sigma_{22 f}}\right)^{2}+\left(\frac{\sigma_{12}}{\sigma_{12 f}}\right)^{2}+\left(\frac{\sigma_{23}}{\sigma_{23 f}}\right)^{2} \geq 1
$$

Failure along 22 plane,

$$
e_{33 f}^{2}=\left(\frac{\sigma_{33}}{\sigma_{33 f}}\right)^{2}+\left(\frac{\sigma_{23}}{\sigma_{23 f}}\right)^{2}+\left(\frac{\sigma_{31}}{\sigma_{31 f}}\right)^{2} \geq 1
$$




\section{Kevlar/epoxy}

Equation of states: Orthotropic

Sub-equation of states: Polynomial

Reference density $\left(\mathrm{g} / \mathrm{cm}^{3}\right): 1.65$

Young's modulus $11(\mathrm{kPa}): 1.948000 \mathrm{E}+006$

Young's modulus $22(\mathrm{kPa}): 1.798900 \mathrm{E}+007$

Young's modulus $33(\mathrm{kPa})$ : $1.798900 \mathrm{E}+007$

Poisons ratio 12: 0.08000

Poisons ratio 23: 0.07560

Poisons ratio 31: 0.69800

Shear modulus $12(\mathrm{kPa}): 2.230000 \mathrm{e}+005$

Shear modulus $23(\mathrm{kPa}): 1.857010 \mathrm{e}+006$

Shear modulus $31(\mathrm{kPa}): 2.230000 \mathrm{e}+005$

Strength: Elastic

Shear modulus $(\mathrm{kPa})$ : $1.857010 \mathrm{E}+06$

Failure: Material stress/strain

Tensile failure stress $11(\mathrm{kPa}): 1.2000 \mathrm{E}+006$

Tensile failure stress $22(\mathrm{kPa}): 1.85000 \mathrm{E}+006$

Tensile failure stress $33(\mathrm{kPa}): 1.85000 \mathrm{E}+006$

Maximum shear stress $12(\mathrm{kPa}): 5.4300 \mathrm{E}+005$

Maximum shear stress $23(\mathrm{kPa}): 7.7000 \mathrm{E}+004$

Maximum shear stress $31(\mathrm{kPa}): 5.4300 \mathrm{E}+005$

Tensile failure strain 11: 0.02000

Tensile failure strain 22: 0.06000

Tensile failure strain 33: 0.06000

Maximum shear strain 12: $1.0000 \mathrm{E}+020$

Maximum shear strain 23: $1.0100 \mathrm{E}+020$

Maximum shear strain 31: $1.0100 \mathrm{E}+020$

Post failure response: Orthotropic

Fail $11 \& 11$ only
Fail 22 \& 22 only

Fail $33 \& 33$ only

Fail $12 \& 12$ and 11 only

Fail $23 \& 23$ and 11 only

Fail $31 \& 12$ and 11 only

Residual shear stiff. fraction 0.20

Erosion: Instantaneous geometric strain

Erosion strain: 1.2

\section{Steel 4340}

Equation of states: Linear

Reference density $\left(\mathrm{g} / \mathrm{cm}^{3}\right): 7.8300$

Bulk modulus (kPa): $1.59 \mathrm{E}+08$

Reference temperature (K): 300

Specific heat capacity: (J/kg K) 477

Strength: Johnson-Cook

Shear modulus $(\mathrm{kPa}): 7.700 \mathrm{E}+07$

Yield stress $(\mathrm{kPa}): 7.92 \mathrm{E}+05$

Hardening constant $(\mathrm{kPa}): 5.10 \mathrm{E}+05$

Hardening exponent: 0.26

Strain rate constant: 0.014

Thermal softening exponent: 1.03

Melting temperature (K): 1793

Failure: Johnson-Cook

Damage constant D1: 0.05000

Damage constant D2: 3.44000

Damage constant D3: -2.12000

Damage constant D4: 0.00200

Damage constant D5: 0.61000 


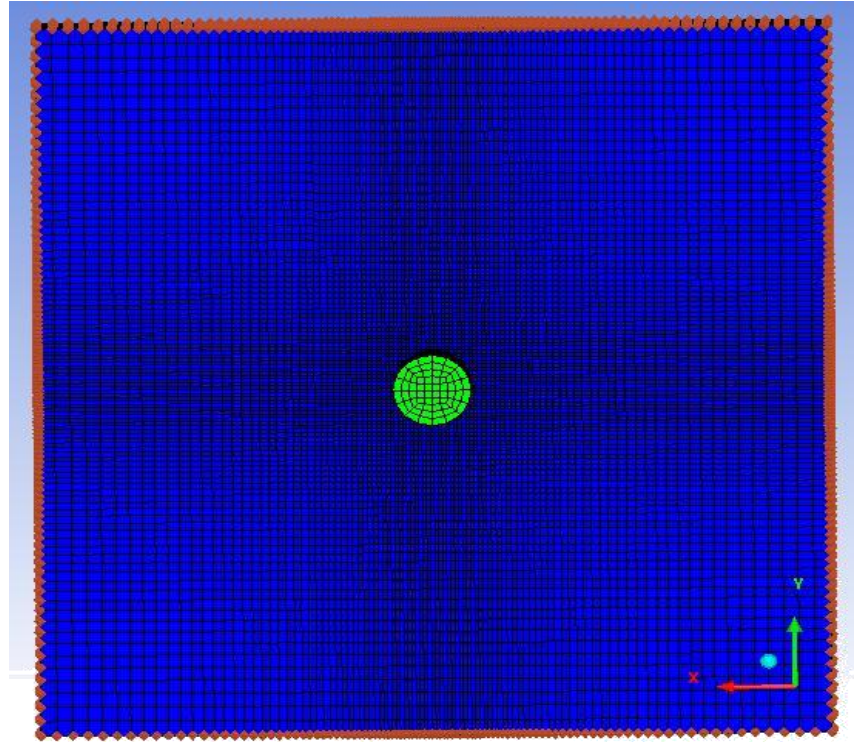

Fig 1 Coordinate system of plate and impactor

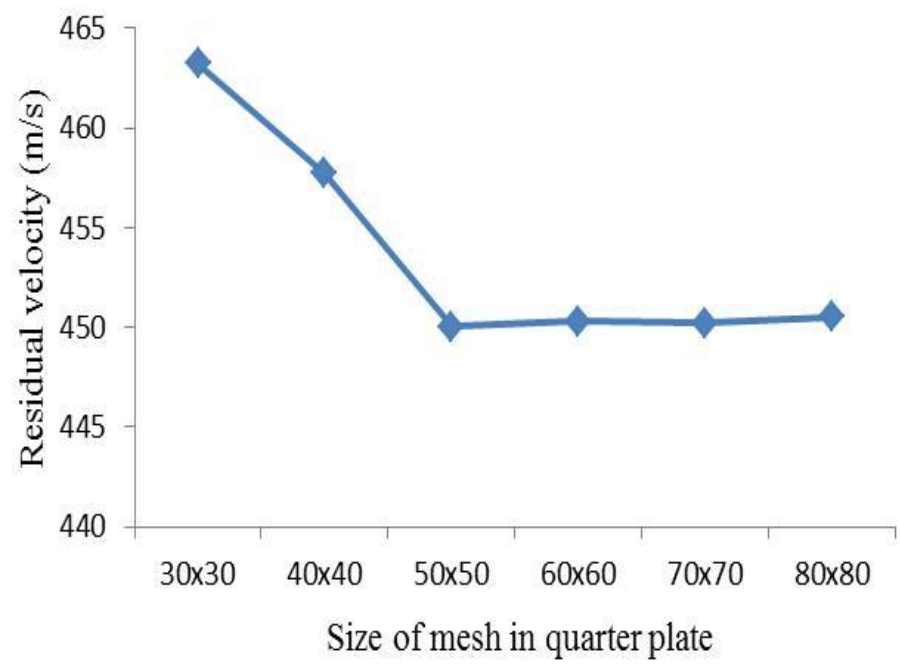

Fig 2 Mesh convergence study of composite plate

\section{RESULTS AND DISSCUSSIONS}

Composite plate (Kevlar/epoxy) of size $100 \mathrm{~mm}$ x100 mm x $10 \mathrm{~mm}$ has been impacted by a conical bullet with apex angle 90 and blunt ended bullet of mass $6.15 \mathrm{gm}$. each. Plate is fully clamped at all the edges. First of all, model is analyzed for ballistic limit for sharp edged conical as well as blunt ended bullet and compared with available literature Wen [9]. Numerical results from present model shows a close agreement as in Table 2.
Table 2. Validation of Numerical model

\begin{tabular}{|c|c|c|c|}
\hline \multirow[t]{2}{*}{ Model descriptions } & \multirow[t]{2}{*}{ Impactor shape } & Present & $\operatorname{Wen}[\theta]$ \\
\hline & & Ballistic limit (m/s) & Ballistic limit (m/s) \\
\hline $\mathrm{T}=10 \mathrm{~mm}, \mathrm{D}=10 \mathrm{~mm}, \sigma_{\mathrm{e}}=$ & Conical, $\theta=90^{\circ}$ & 305 & 297 \\
\hline $\begin{array}{l}130 \mathrm{MPa}, \mathrm{P}_{t}=1650 \\
\mathrm{~kg} / \mathrm{m}^{3},\end{array}$ & Blunt, $\theta=180^{\circ}$ & 323.5 & 322 \\
\hline
\end{tabular}

To study the ballistic limit and the variation of impactor velocity, the impactor with incidence velocities between 100$1000 \mathrm{~m} / \mathrm{s}$ is impacted on composite plate as shown in Figure 3 . Impactor with incidence velocity below $320 \mathrm{~m} / \mathrm{s}$ is showing negative value of velocity after time 0.09 millisecond and it implies that the impactor rebound back after some penetration in composite plate. For Incidence velocity of $322 \mathrm{~m} / \mathrm{s}$ and above, the impactor shows positive values that become constant after certain time.

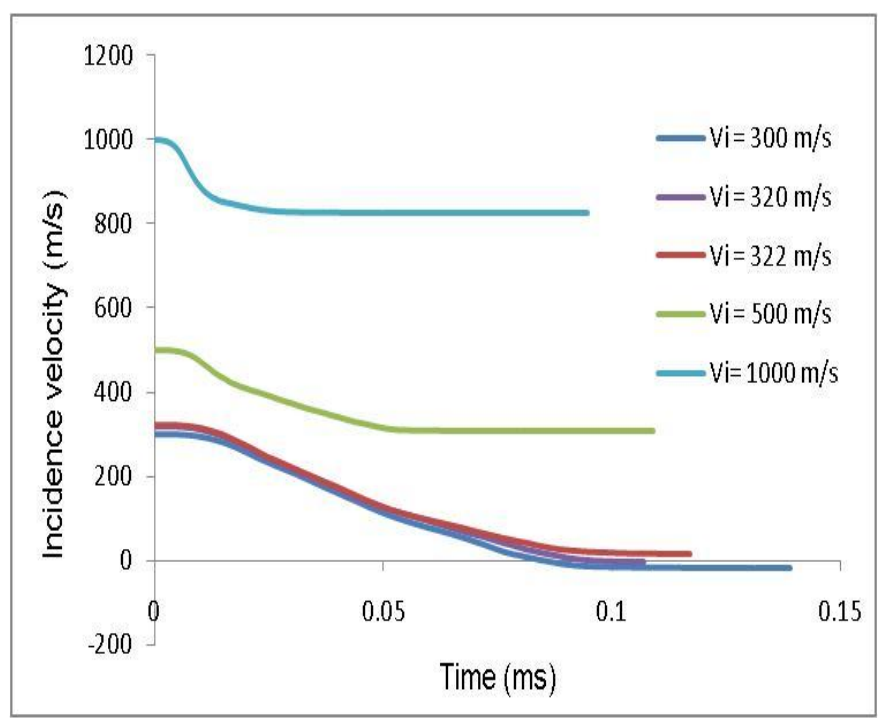

Fig 3 Variation of impactor velocity with time

To study the damage evolution i.e. modes of damages in the composite plate due to impact, plate is impacted by conical as well as blunt ended bullet at incidence velocity of $500 \mathrm{~m} / \mathrm{s}$ as shown in the cross sectional view in Figure 4. Damage in the composite plate occurs mainly due to delamination caused by tensile force in the thickness direction. Shear failure is the second largest mode of damage as shown in Figure 4(c-d). Bulk failure occurs in initial stage as bullet start to penetrate. Despite of modes of failure in composite plate due to impact by conical and blunt bullet, delamination of lamina and damaged area is more in the case of blunt bullet impact. 


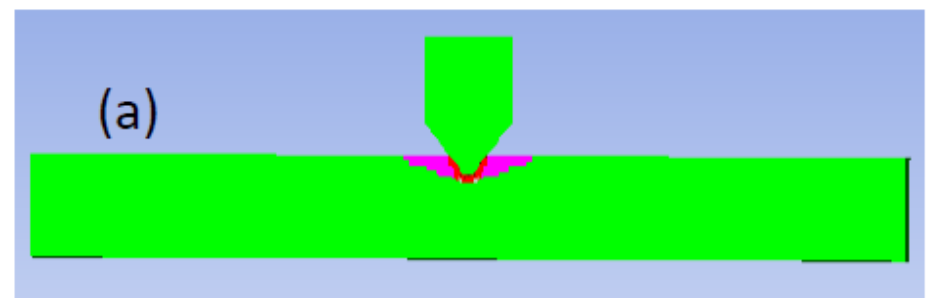

At $\mathrm{t}=0.00562 \mathrm{~ms}$

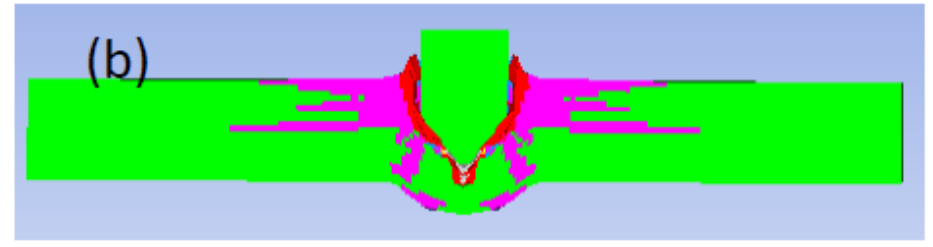

At $\mathrm{t}=0.0199 \mathrm{~ms}$

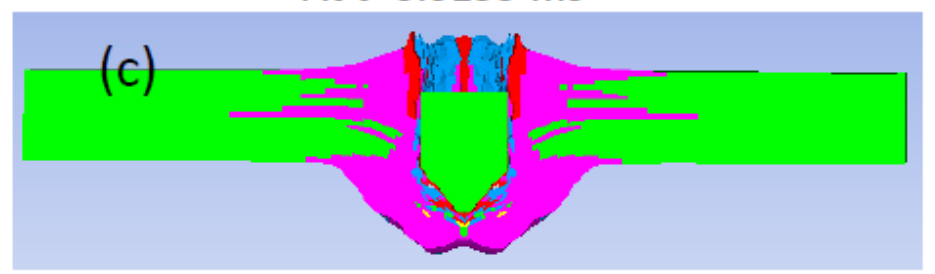

At $\mathrm{t}=0.0393 \mathrm{~ms}$

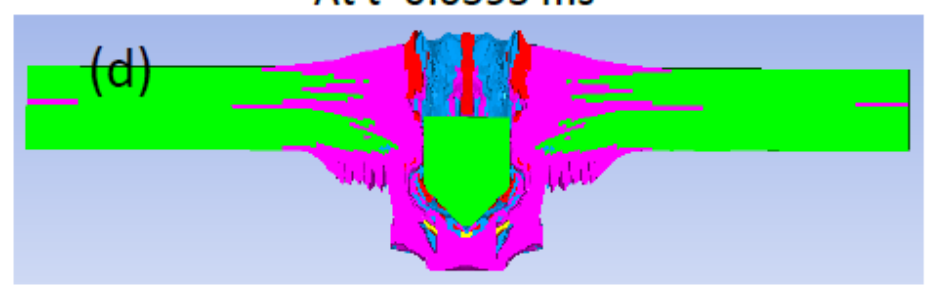

At $\mathrm{t}=0.0505 \mathrm{~ms}$
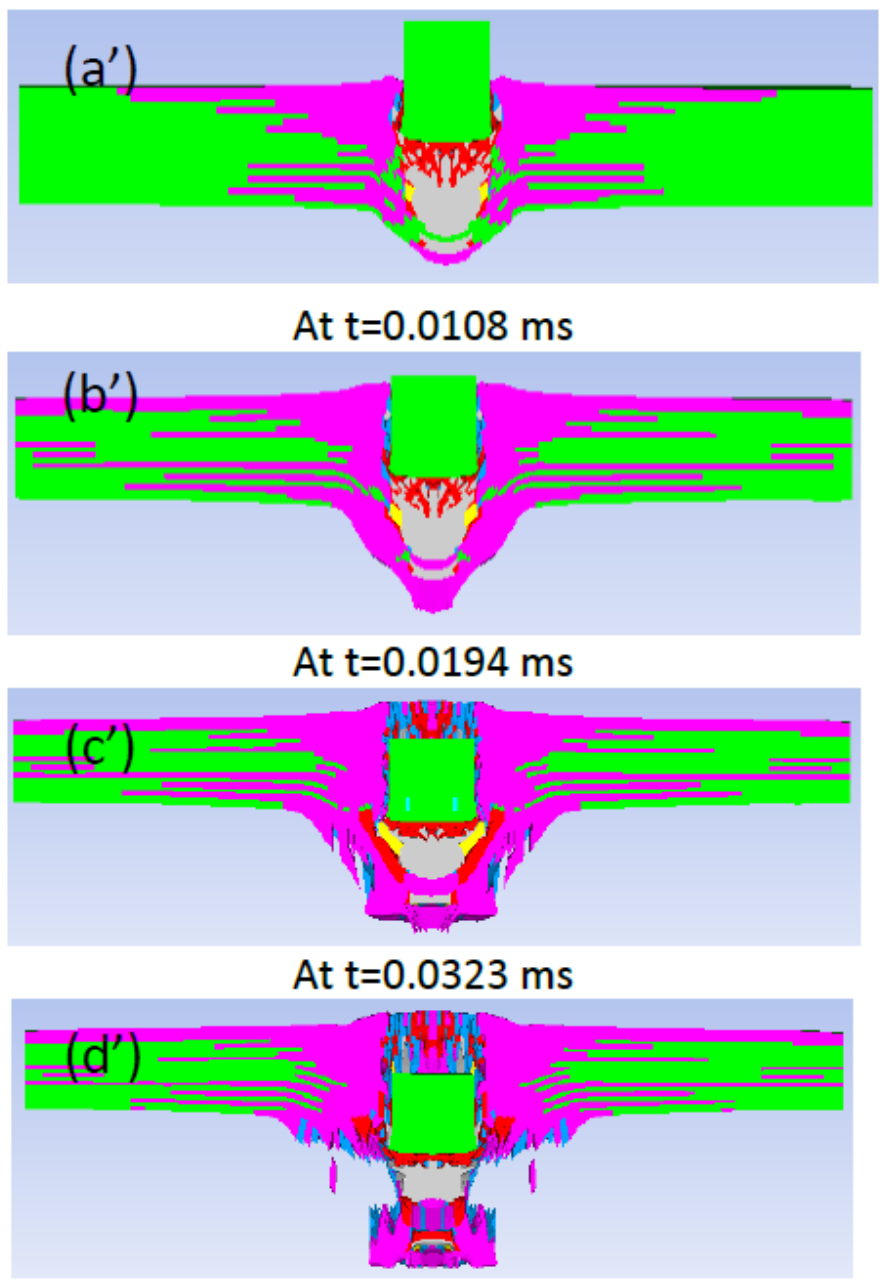

At $\mathrm{t}=0.0427 \mathrm{~ms}$



Fig 4. Damage evolution in composite plate at different time for incidence velocity $500 \mathrm{~m} / \mathrm{s}$; (a-d) conical impactor, (a'-d') blunt impactor

\subsection{Effect of h/a Ratio on Ballistic Limit}

To study the effect of $h / a$ ratio on the ballistic limit of FRP composite plate, a plate (Kevlar/epoxy) of size $100 \mathrm{~mm} \times 100$ $\mathrm{mm}$ with different $\mathrm{h} / \mathrm{a}$ ratios has been impacted by conical as well as blunt ended impactor of mass $6.15 \mathrm{gm}$. Ballistic limit increases linearly with $h / a$ ratio for the conical impactor as shown in Figure 5(a) and nature of variation has good agreement with literature [7]. But in the case of blunt ended bullet, the ballistic limit increases parabolically upward as in Figure 5(b). 

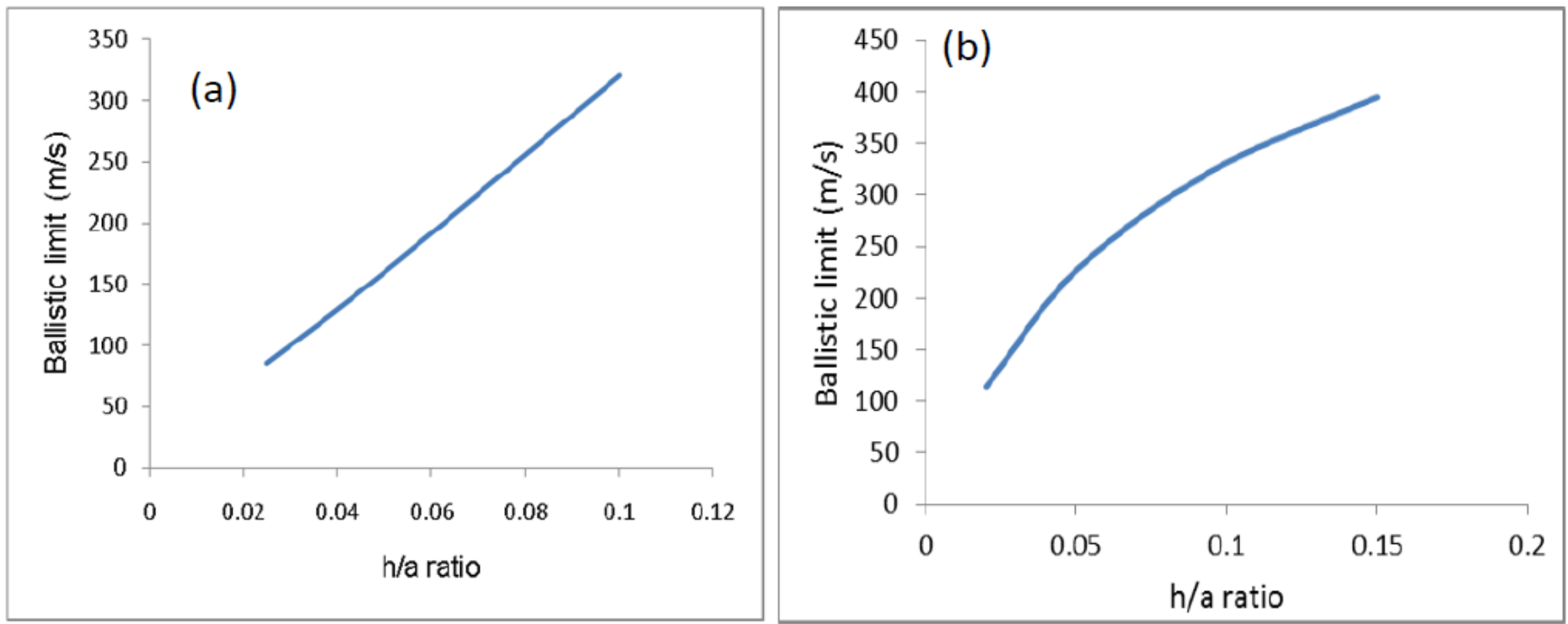

Fig 5. Variation of ballistic limit with $h / a$ ratio of plate (a) conical impactor, (b) blunt impactor

\subsection{Effect of Impactor Nose Shape on Impact}

\section{Behavior}

Composite plate of size $100 \mathrm{~mm} \times 100 \mathrm{~mm} \times 10 \mathrm{~mm}$ has been chosen to impact with conical as well as blunt ended impactor, to study the effect of impactor nose on ballistic behavior of FRP composite. Composite plates are impacted by these two impactors with incidence velocities between $250 \mathrm{~m} / \mathrm{s}$ to 1000 $\mathrm{m} / \mathrm{s}$ and found that residual velocities are more for conical impactor in all the cases as in Figure 6(a). Time taken by blunt ended impactor to perforate the composite plate is more as compared to conical impactor. Loss of kinetic energy is more in the case of impact by blunt ended bullet and this may be the reason for more damage in the composite plate as shown in Figure 7. On the front face of composite plate, more fibers are eroded due to impact by blunt bullet and this is due to the larger area of impactor at impact point. Failure due to out of plane shear force is dominant in the case of impact due to conical impactor.
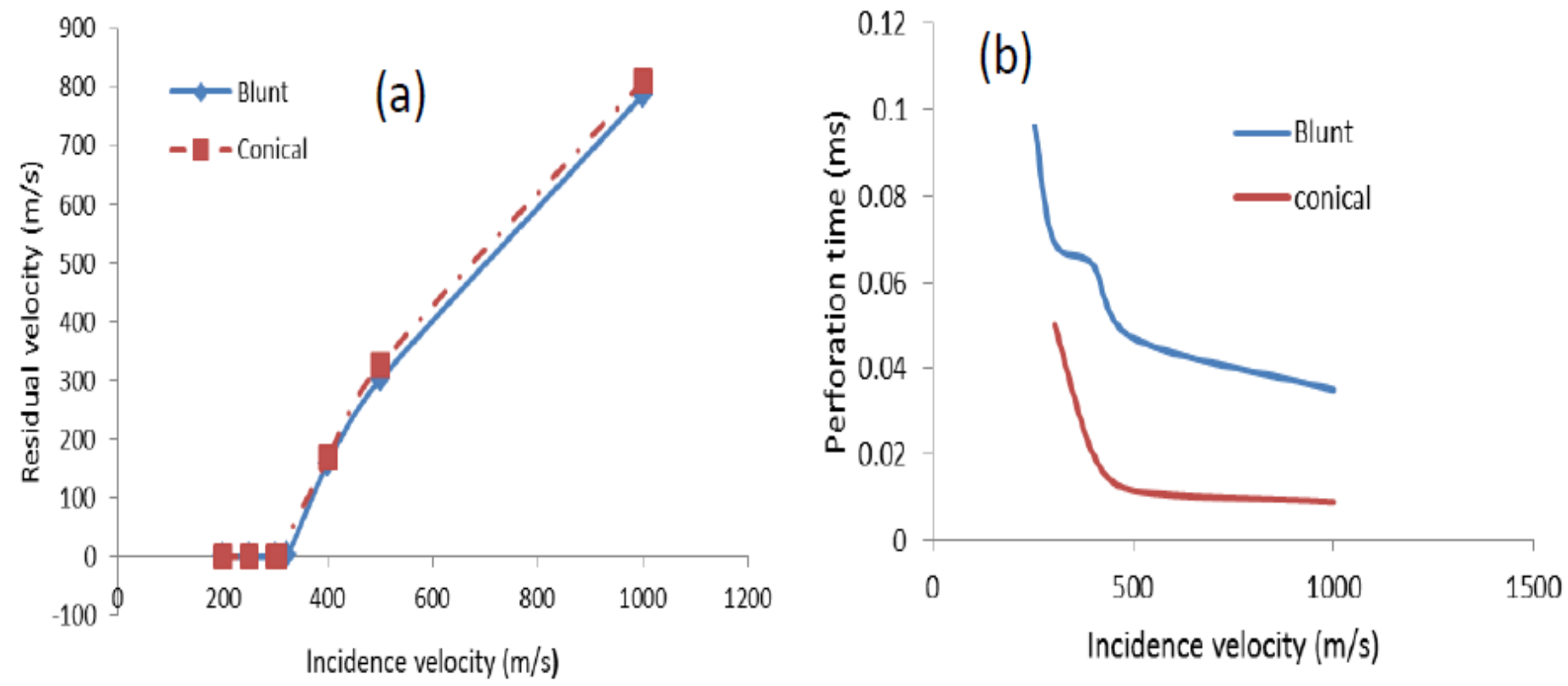

Fig 6. (a) variation of residual velocity with incidence velocity for blunt and conical impactor, (b) variation of perforation time of blunt and conical impactor 


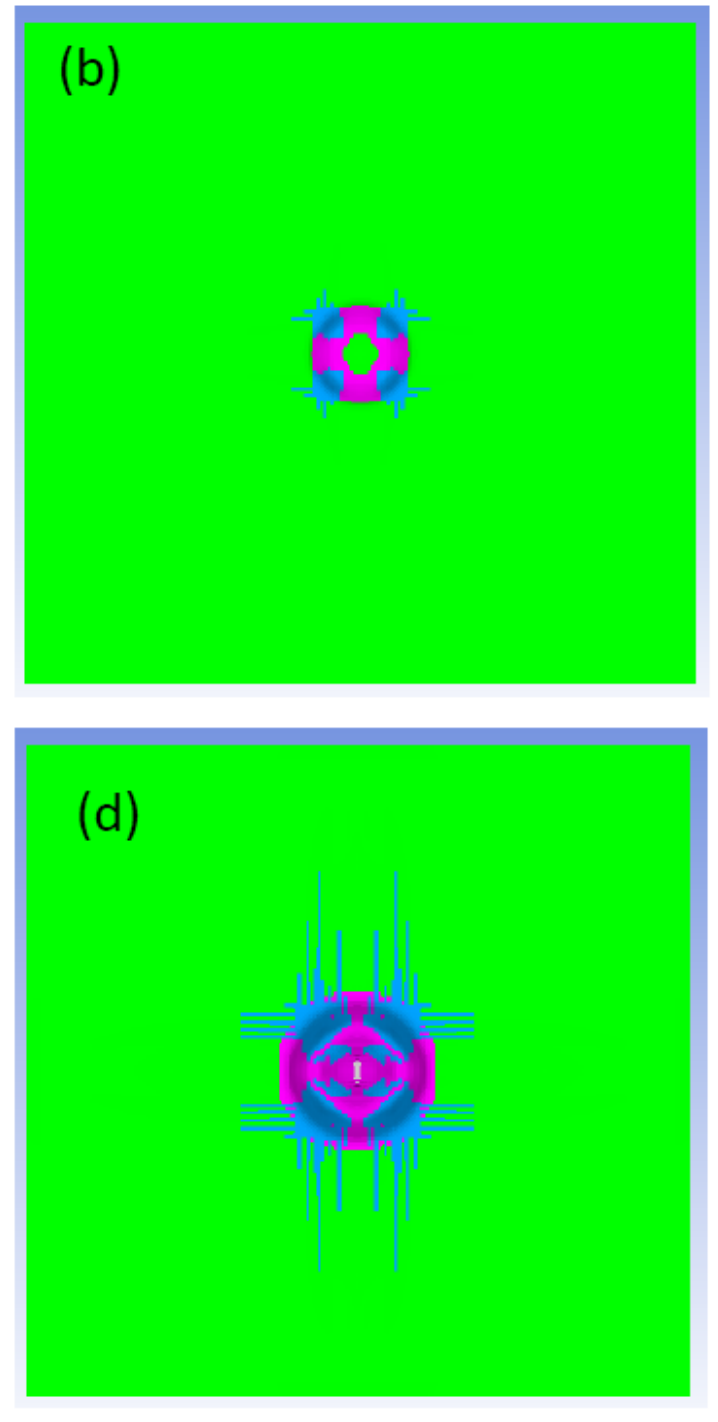

Fig 7. damage pattern in composite plate, (a) front face with conical, (b) back face with conical, (c) front face with blunt, (d) back face with blunt

\section{COCLUSION}

An investigation to study the progressive damage behaviour of FRP composite (Kevlar/epoxy) has been carried out. Composite plate was impacted by conical as well as blunt shaped impactor under fully clamped condition. All the numerical results have been carried out using ANSYS/AUTODYN v14.5. Modes of failure and damage behavior of composite plate due to impact has been studied and it is concluded that the damage occur mostly due to delamination. Shock effect is also incorporated in the analysis to converge the impact problem with what actually happening in the experimental work. The effect of $h / a$ ratio and impactor nose shape on the ballistic limit, residual velocity as well as damage pattern have been studied. Ballistic limit velocity increases more rapidly for conical impactor than blunt ended impactor for different values of $h / a$ ratio.

\section{NOTATIONS}

a span length of Kevlar/epoxy plate

$\sigma_{\mathrm{ij}} \quad$ Stress in $\mathrm{i}, \mathrm{j}$ direction

h thickness of Kevlar/epoxy plate

$\mathrm{h} / \mathrm{a} \quad$ thickness to span ratio of plate

$V_{i} \quad$ incidence velocity of impactor

$\mathrm{V}_{\mathrm{r}} \quad$ residual velocity of impactor

$\mathrm{V}_{\mathrm{b}}$ ballistic limit velocity of impactor 


\section{REFRENCES}

[1] Zhu, G., Goldsmith, W. and Dharan, C.K.H., "Penetration of laminated Kevlar by projectile-1, Experimental investigation" Int. J. of Solids and Struct., V.29, 1992, pp. 399-420.

[2] Muhi, R.J., Najim, F. and Moura, M.F.S.F.D., "The effect of hybridization on the GFRP behavior under high velocity impact", Int. J. of Impact Engg., V. 40, 2009, pp. 798-803.

[3] Gover, H.L., Cronin, D.S. and Plumtree, A., "Ballistic impact response of laminated composite panels", Int. J. of Impact Engg, V. 35, 2008, pp. 1000-1008.

[4] Minh, C.H., Imad, A., Kanit, T. and Boussu, F., "Numerical analysis of a ballistic impact on textile fabric", Int. J. of Mechanical Science, V. 69, 2013, pp. 32-39.

[5] Kumar S, Gupta DS, Singh I and Sharma A. Behavior of Kevlar/Epoxy Composite Plates under Ballistic Impact. Materials and Design. 2010; 29: 2048-2064.

[6] Tham, C.Y., Tan, V.B.C. and Lee, H.P., "Ballistic impact of a Kevlar helmet: experimental and simulations", Int. J. of Impact Eng., V. 35, 2008, pp. 304-318.

[7] Talib, A.R.A., Abbud, L.H., Ali, A. and Mustapha, F., "Ballistic impact performance of Kevlar-29 and $\mathrm{Al}_{2} \mathrm{O}_{3}$ powder/epoxy targets under high velocity impact", Materials and Design, V. 35, 2012, pp. 12-29.

[8] Landa, B.P. and Olivers, F.H., "An analytical model to predict impact behavior of soft armor", Int. J. of Impact Eng., V. 16, 1995, pp. 455-466.

[9] Wen, H.M., "Predicting the penetration and perforation of FRP laminates struck normally by projectiles with different nose shapes", Compos Struct., V. 49, 2000, pp. 321-329.

[10] Wen, H.M., "Penetration and perforation of thick FRP laminates", Compos. Sci. and Tech., V. 61, 2001, pp. 1163-1172.

[11] Hayhurst, C.J., Livingstone, I.H.G. and Clegg, R.A., "Ballistic limit evaluation of advanced shielding using numerical simulations", Int. J. of Impact Eng., V. 26, 2001, pp. 309-320.

[12] Johnson, G.R. and Cook, W.H., "Fracture characteristics of three metals subjected to various strains, strains rates, temperature and pressure", Eng. Frac. Mech., V. 21, 1985, pp. 31-48. 